\title{
UNA PROPUESTA RELECTURA DE LAS PINTURAS DEL CAMARÍN DE LA SANTA FAZ DE ALICANTE
}

\author{
A PROPOSAL TO READ THE PAINTINGS OF THE \\ DRESSING ROOM OF THE SANTA FAZ OF ALICANTE
}

\author{
Joaquín Barceló Orgiler \\ (Universidad de Valencia, España) \\ joaquinbarcelo@uv.es
}

Recibido: 12 febrero 2020 Aceptado: 10 marzo 2020

\begin{abstract}
Resumen: Los óleos con "históricas escenas" de la Santa Faz realizados por Juan Conchillos Falcó (1641-1711) para el camarín del Monasterio de la Santa Verónica (Alicante) son uno de los elementos más destacados de su producción. Sin embargo, pese a su excelente estado de conservación, su importancia y, sobre todo, su gran narratividad, apenas han sido estudiados. Por ello, en las siguientes páginas se propone una nueva interpretación del significado de las mismas en base a las fuentes de la época y las circunstancias en que fueron, intentando analizar su significado y su importancia para la reivindicación de la latría absoluta a la santa Faz.
\end{abstract}

Palabras clave: Conchillos, Santa Faz, pintura de historia, pintura valenciana del siglo XVII, Alicante.

\begin{abstract}
The oil paintings with scenes of the history of the Alicante's Santa Faz made by Juan Conchillos Falcó (1641-1711) for the Monastery of Santa Verónica (Alicante) are one of his masterpieces. However, despite their excellent state of preservation, their importance and, particularly, their narrativity, they have hardly been studied. Therefore, in the following pages a new interpretation of the meaning of the same is proposed based on the contemporary sources and the circumstances in which they were done, trying to analyze their meaning and their importance for the reivindication of absolute latry to the Holy Face made by Alicante's council.
\end{abstract}

Keywords: Conchillos, history painting, XVIIth century valencian painting, Alicante. 


\section{INTRODUCCIÓN}

Los óleos con "históricas escenas" de la Santa Faz realizados por Juan Conchillos Falcó (1641-1711) para el camarín del Monasterio de la Santa Verónica (Alicante) [1] son uno de los elementos más destacados del mismo. Sin embargo, pese a su excelente estado de conservación, su importancia y, sobre todo, su gran narratividad, apenas han sido estudiados1. Igualmente, estos lienzos no se han relacionado ni con las políticas de defensa de la latría absoluta a la Santa Faz contemporáneas a su confección y emprendidas por su comitente, el Consell de la ciudad de Alicante, para recuperar el culto a la reliquia derogado en 1623, cuyos argumentos conocemos gracias a la Dissertación escrita por el jesuita Jospeh Fabiani en 1750, ni con las reivindicaciones de la ciudad de obtener su propia sede catedralicia e independizarse de Orihuela, en cuya gobernación se encontraba (Cutillas, 1996, p.48). Por ello, en las siguientes páginas se propone una nueva interpretación del significado de las mismas en base a este texto en el cual se narran con minuciosidad los mismos momentos plasmados por el pincel de Conchillos2.

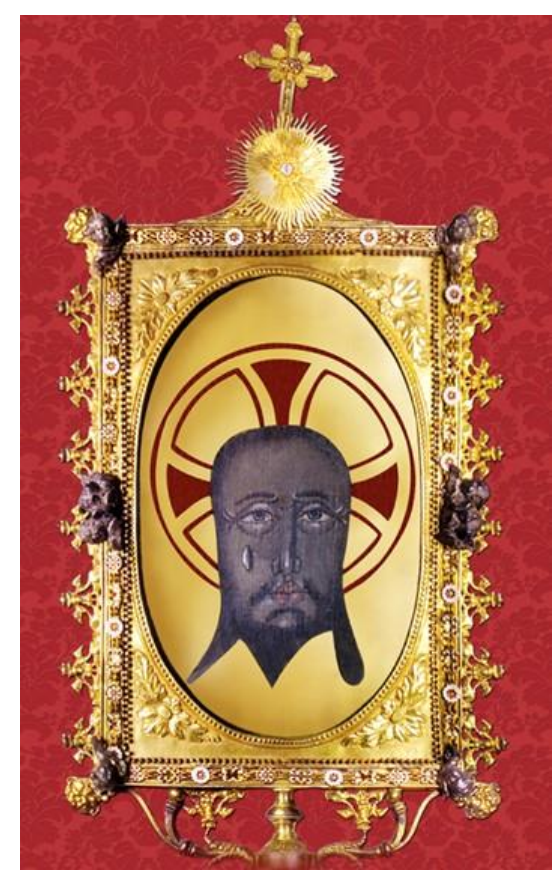

1. Santa Faz

\footnotetext{
1 Un breve estado de la cuestión de las publicaciones que han tratado el Camarín de la Santa Faz comprendería las publicaciones de Bernabé Vidal, Hernández Guardiola y Sáez Vidal recogidas en las referencias finales.

2 El siguiente artículo sigue la metodología de una serie de estudios que han revelado la importancia de las imágenes achiropoietas y en particular de las múltiples Santas Faces, teniendo como referencias los estudios de Belting, Stoichita y Pereda (citados en las referencias finales).
} 


\section{LA CONSTRUCCIÓN DEL CAMARÍN}

El camarín de la Santa Faz es el elemento más antiguo del monasterio actual que fue edificado mediante un largo proceso constructivo culminado hacia 1760 (Varela, 2006, p.44). Este espacio es el único elemento superviviente del ábside poligonal de la iglesia perteneciente a la reforma que las clarisas realizaron entre 1557 y 1589 sobre el antiguo monasterio jerónimo situado en el lugar donde sucedió el primer milagro de la reliquia, el de la lágrima. La decisión de crear un espacio donde guardar la Santa Faz se tiene constatada desde la sesión del Consell del 6 de noviembre de 1661 en la cual el cabildo municipal alicantino, aunque no se pudo concretizar hasta la década de 1680.

\section{UN BREVE REPASO A LA DEVOCIÓN DE LA RELIQUIA}

Pese a que no se tengan noticias de la Santa Faz hasta su aparición en Alicante en las últimas décadas del siglo $\mathrm{XV}$, la tradición establece que la verónica alicantina es una de las tres "Santas Faces" reconocidas por la iglesia, impresas sobre el paño de la Verónica durante la pasión de Cristo. Para ello, a partir de 1489 se identificó la Santa Faz de Alicante con la de Jerusalén, había desaparecido en Roma unas décadas antes y que por diverso designio divino había aparecido en la ciudad levantina.

La Santa Faz de Jerusalén, es aquel paño que se veneró desde la oficialización del cristianismo en esta ciudad hasta la conquista musulmana de Jerusalén en el 638 cuando fue llevada a Chipre, pasando a Constantinopla cuando los turcos tomaron la isla (Esplá, 1962, p.28). Allí, se guardó hasta que fue regalada por los hijos de Constantino IX Paleólogo al papa Nicolás V por concederles refugio tras la caída del Imperio Bizantino, quien colocó el Santo Lienzo en el oratorio papal (Sala, 1989, p.73). Su sucesor Sixto IV, de origen veneciano prestó la reliquia a su ciudad natal en 1483 para que cesase la epidemia de peste que estaba asolando a la misma, siendo portada hasta este lugar y custodiada por un cardenal (Ibídem). Cuando este fue a devolverla a Roma se enteró de que el sumo pontífice había fallecido, quedándose con la preciada reliquia. Perdiéndose así, "oficialmente" la pista de la misma hasta la actualidad. 
Sin embargo, un lienzo de las mismas características le fue regalado por un cardenal en Roma en el año 1484 a mosén Pedro de Mena cura de Sant Joan d'Alacant en agradecimiento a los servicios prestados, quien retornó a Alicante con ella (Ibídem). Este sacerdote la llevaría a la parroquia de Sant Joan donde la guardaría junto al ajuar de la iglesia en el fondo de un arca, pero tras diversos prodigios decidió hacerla un objeto de veneración en la iglesia. Tanta fue la devoción creada en torno a ella que a principios de marzo de 1489 se le realizó una rogativa para que lloviese y al concederse lo pedido, el día 17 fue sacada en procesión como agradecimiento, dándose el primer milagro, el de la lágrima (Esplá, 1962, p.30). Tras este primer milagro, se hizo otra peregrinación el jueves de la semana posterior, en la que fray Benito de Valencia dio una predicación en la que se exhortaba a la piedad y al arrepentimiento, sucediendo posteriormente el "milagro de las tres faces" o la epifanía de la Santa Faz", el más importante de los obrados por la reliquia pues fue aquel que sería usado para explicar porque se trataba de la verdadera verónica de Jesucristo (ibídem). Ya que esta situación fue interpretada como:

"Disponiendolo Dios assi, para que quanto menos se podía esperar en lo humano, atendidas todas las circustancias, se creyesse tanto mas fácilmente, y con indubitables fundamentos, quantas son las patentes maravillas que se siguieron, que Dios quería regalar, en colocar en esta Ciudad [de Alicante] la Sagrada Faz de Jesus, impressa en uno de los tres dobles del lienzo de la Santa Veronica” (Fabiani, 1763, p.23).

Así, aunque no fuera oficializado por la iglesia, se fue asentando el culto a la Santa Faz como el verdadero rostro de Cristo, identificándola con la de Jerusalén, pero sin que existiese ninguna prueba fehaciente de que fuera esta, más allá de la tradición. De esta manera, el culto a la Santa Faz fue paulatinamente asentándose tras la bula de indulgencias de Inocencio VIII de 1490 y la aprobación de la cofradía en 1496 por Fernando el Católico, siendo oficializado con el Viva vocis oráculo de Clemente VII de 1525, contando con su propio rito de Doble Mayor realizado cada 17 de marzo y convirtiéndose en la principal de la ciudad (Cutillas, 1996, p.48). Sin embargo, el papa Urbano VII, aplicando la reforma de Pío V, abolió su culto, por heterodoxo, mediante un breve el 20 de diciembre de 1631 (Ibídem). Algo que no fue bien acogido en la ciudad y el oficio siguió celebrándose por lo menos hasta el siglo XVIII (Esplá, 1962, p.30). 
El cabildo municipal promocionó entre 1685 y 1697 un proceso en la Sagrada Congregación de Ritos tanto de Orihuela como de Roma para verificar la reliquia y que fuera considerada como la Santa Faz de Jerusalén y por lo tanto, auténtica (Cutillas, 1995, p.48). Para ello, presentaron varias pruebas de su autenticidad, en un proceso en el cual se sitúa la creación del Camarín. En 1688 nombraron a Jaume Llop, como síndico para que demostrase ante el obispado la veracidad de la reliquia, elaborando para ello, la Información ad perpetuam rei memoriam y encargando a los pintores Pere Joan Valero dorador del camarín- y Joseph Sempere un estudio y descripción del Santo Rostro para determinar si era de origen humano. De esta conservamos solamente un fragmento del documento que llevó en 1689 Jaume Llop a Roma, trascrito por Fernado Valero, hijo del pintor:

"Mi señor padre Don Pedro Juan Valero [...] constituido en la Sacristía de dicho Convento, hizo que un Padre Sacerdote [...] sacase de su Sagrario la Santíssima Faz y quitada la cristalina vidriera, [...] la contempló a toda su satisfacción, notando en ella quantos ápices havia, para formar su atestación que reduxo á la substancia siguiente: que la Tela [...] no era tafetán, sino como muy fina gaza, como patentemente se reconocía en ella; que lo relativo á las megillas, frente y parte de la barba, no se reconocia colorido lo más mínimo sobrepuesto por el pincel, sino imprimación como de sangre, viéndose distintíssimamente todos los hilos del texido; pero á lo que comprehendía, los Antiguos, queriendo dar más forma de Rostro a aquella imprimación retocaron con pincel las cejas, labios y parte de la barba, según se percibía evidentemente” (Fabiani, 1763, pp.44-45).

Este mismo año de 1688 el ayuntamiento se puso en contacto con el Marqués de Cogolludo, embajador de España ante la Santa Sede para que defendiese su causa (Martínez, 1953, pp.2-3). Ante la negativa de este escribieron en 1694 a Carlos II, quien apelaría al Marqués de Medinaceli, embajador en la Santa Sede y al Cardenal Cibo. A pesar de los deseos del monarca y los intentos del Consell, la Sagrada Congregación de Ritos no reconoció a la Santa Faz como auténtica (Cutillas, 1996, p.55). No obstante, la polémica siguió a lo largo del siglo XVIII y en 1794 se autorizaría finalmente que la reliquia tuviese un culto especial por la Sagrada Congregación de Ritos siempre que se admitiese que era una copia de la de Roma. 


\section{"VISTO Y OÍDO POR TRADICIÓN PÚBLICA INMEMORIAL": LOS LIENZOS DE CONCHILLOS Y LA LEGITIMACIÓN DE LA SANTA FAZ}

Los lienzos que decoran el Camarín se encuentran distribuidos en dos grupos, el primero lo forman aquellos que decoran las paredes y que narran los milagros de la Santa Faz en la ciudad de Alicante demostrando que era la verdadera verónica de Cristo. Las pinturas sobre los milagros de la Santa Faz representan los sucesos más destacados de la historia de Alicante en este momento, acontecidos correlativamente los días 17 y 24 de marzo (el milagro del 31 de marzo no se representa en este espacio). El entendimiento de los milagros de la Santa Faz como el suceso más importante de la historia local de Alicante se encuentra en las primeras fuentes que los narran, como la Crónica de Valencia (Viciana, 1562, p.169). De ella, dos ideas son especialmente interesantes para nuestro análisis de este conjunto pictórico: el monasterio como un patronato municipal y la insistencia en el elevado número de personas que se congregaron para honrar a la Santa Faz. Este último pensamiento, es el que debe de regirnos para entender los grupos de personas apreciables en la obra de Conchillos como un intento de recreación de lo sucedido buscando la identificación entre la ciudadanía de Alicante y la Santa Faz (Cutillas, 1995, p.39). A este planteamiento deberíamos ligar la necesidad de legitimar los milagros a través de los testigos visuales de los mismos, pues como se expresaba en Illice ilustrada, el culto a la Santa Faz se había afirmado por lo

\footnotetext{
“oído por tradición pública e inmemorial, heredada de sus padres y mayores, los prodigios y milagros que [...] ante ellos obró el Soberano Rostro y que eran públicos y notorios públicos y notorios en esta ciudad y Reinos de España" (Maltés \& López, 1991 ed. p.709).
}

El primer lienzo muestra el Milagro de la Lágrima [2] ocurrido el 17 de marzo de 1489. Hernández Guardiola ha indicado que su representación difiere en algunos elementos de la Informació realizada por Jaume Llop en 1689, posterior a la confección de las pinturas (Hernández, 1994, p.43). Esta situación se debe a que están más relacionada con los escritos recogidos en la Crónica de Bendicho y otros publicados hasta el momento de su realización que narraban este milagro. En la pintura se muestran dos grupos contrapuestos y unidos entre sí mediante la Santa Faz, representándose en la mitad 
derecha al padre fray Villafranca con la verónica en sus manos, siendo sustentado por otro franciscano y el cura de Mutxamel (Ibídem, p.47). En la otra mitad de la escena se puede ver a mosén Pedro de Mena vestido con casulla y al resto de la procesión proveniente de un caserío que representa el pueblo de Sant Joan d'Alacant. La aparición del sacerdote de Mutxamel, se explica porque el milagro de la Santa Faz puso fin a las disputas territoriales entre ambas poblaciones tras él pues "fue tanta la compunción de las gentes [...] que los de San Juan y Muchamiel se abrazaron y se perdonaron mutuamente los agravios" (Maltés \& López, 1991 ed., p.183).

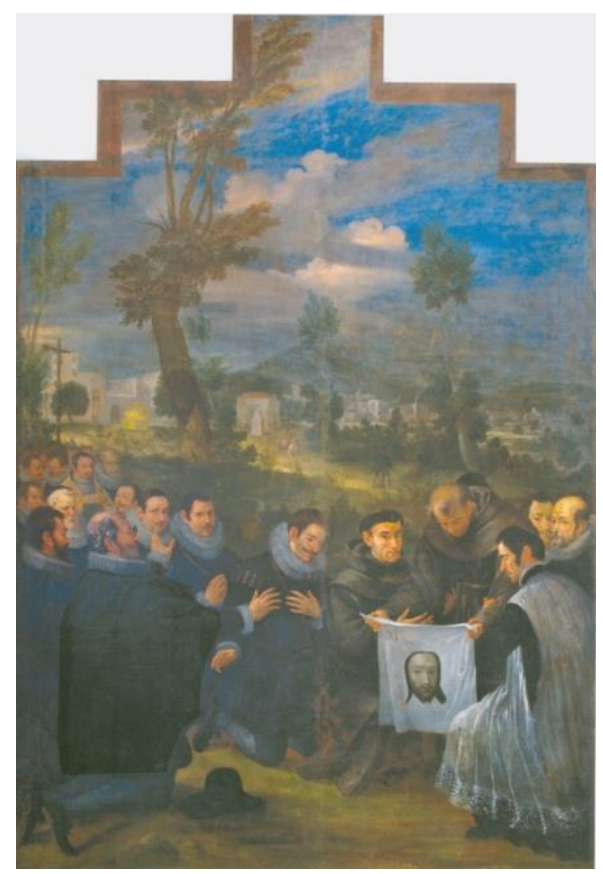

2. Juan Conchillos Falcó. El milagro de la lágrima, ca.1677-1680. Óleo sobre lienzo. 338 x 238 cm. Monasterio de la Santa Faz (Alicante)

La existencia de estos personajes, la conocemos por Fabiani que indicó:

"La Santa Reliquia la llevaba en su mano [...] el P. Villa-Franca [...] quien, quedando sin movimiento en los pies, empezóá dar vozes, y pedir socorro. Acudió el otro Religioso su compañero, y un sacerdote de Muchamiel, quienes, tomando los brazos del Padre Villafranca, le sostuvieron" (Fabiani, 1763, p.28).

De este lienzo, al igual que del conjunto de las pinturas, destaca su concienzuda representación de la topografía, representando especies vegetales endémicas y una arquitectura vernácula, nada estandarizada y para lo cual Conchillos debió de realizar 
estudios previos minuciosos de estos elementos (Hernández, 1988, p.54). En un lateral se muestra a un caballero que extiende las manos hacia la verónica y del cual también nos informa Fabiani:

"Entre los muchos, que habían concurrido á admirar el prodigio de la lágrima, se hallaba un Cavallero de Alicante, que deseoso de certificarse más, de si era verdadera lagrima, ó deslumbramiento de los ojos de todos, se atrevió á tocarla con uno de sus dedos, y viendo, que esta se reventó al contacto, quedó confirmado en la verdad del milagro, y dio testimonio de él, todo el resto de su vida, porque llevó siempre un dedal de plata en aquel dedo, por respeto y reverencia a la [...] venerada Faz del Señor. Este Cavallero, es constante tradición, que fue D. N. Pasqual, dueño de aquel territorio, en donde sucedió este prodigio y donde al presenta está la Iglesia y Convento de la Santa Faz” (Ibídem).

La segunda pintura es la Predicación de fray Benito de Valencia [3] y representa el sermón realizado el día 24 de marzo de 1489. En él se muestra en un primer plano a la población de Alicante que había acudido en masa a escucharlo y tras ellos al propio fraile, cobrando en este lugar gran importancia los elementos topográficos fácilmente reconocibles, también plasmados en el lienzo del Milagro de las Tres Faces y que reproducen de manera fidedigna el aspecto del Pla del Bon Repós en el setecientos.

Este momento no se narra en profundidad ni en la Chronica de Marcos de Lisboa ni en el Doble Rezo, pero de las palabras de Fabiani se comprende su importancia la mentalidad popular alicantina del momento:

“Aquí subió [al púlpito] el V. Fr. Benito, teniendo á su lado con la posible decencia la Santa Faz. Dividió su Sermón en tres puntos. Fue el primero en ponderar la gravedad del pecado mortal, que tanto desagrada á Dios, y le mueve á castigar a los Pecadores con tribulaciones, especialmente con la sequedad. El segundo, fue, la eficacia de la verdadera penitencia. El tercero, los raros y singulares medios, que elige la Divina Providencia, para excitar la contrición del corazón, y el espíritu de la penitencia en las almas. Y como al ir concluyendo este tercero punto, contrajese sus dichos determinadamente á la Santa Faz, diciendo: Ser ella el 
instrumento que Dios havía elegido en aquella sazón para mover a penitencia los corazones, hizo, que se la alcanzasen, y mostrándola al Pueblo, lo exortaba fervorosamente, y le esperanzaba de la misericordia de Dios, y del beneficio de la deseada lluvia, si verdaderamente lloraba y se arrepentía de sus pecados" (Fabiani, 1763, p.30).

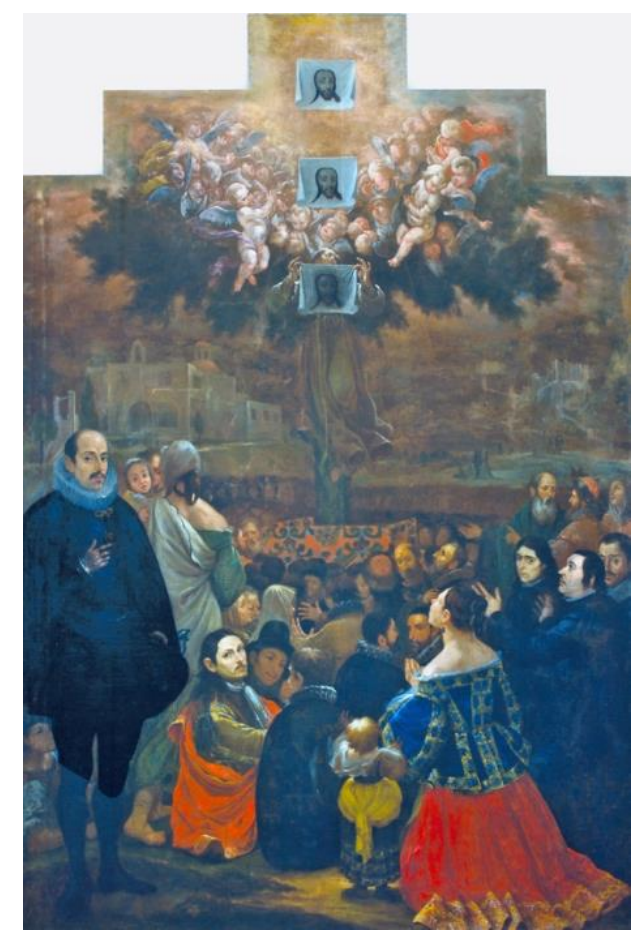

3. Juan Conchillos Falcó. La predicación de Fray Benito de Valencia, ca.1677-1680. Óleo sobre lienzo. 338 x $238 \mathrm{~cm}$. Monasterio de la Santa Faz (Alicante). En primer plano sentado y señalando a Fray Benito Hernández Guardiola ha identificado un supuesto autorretrato de Conchillos.

A la derecha del lienzo se plasma el Convent dels Àngels, cenobio franciscano fundado hacia 1440 y de gran importancia, pues en él se guardaba una pintura de la virgen que se creía anterior "a los moros” (Ibídem). El deán Bendicho explicó sobre ella que "los godos, viendo la tiranía de los moros y pensando que durarían poco en la península, no tuvieron más remedio que enterrarla" (Bendicho, 1960 ed., p.64), habiendo sido esta desenterrada por ángeles y mostrada a un leñador, que cuando la encontró dio fe de ella en la ciudad (Fabiani, 1763, p.75). Posteriormente se construyó un monasterio y la imagen fue cuidada por los franciscanos, siendo una de las devociones principales de la ciudad porque demostraba su "christiana antigüedad" (Ibídem). 
En el centro de la imagen se puede observar el llamado Pi Sant, cuyo tocón se venera en la actualidad en el interior de la iglesia del monasterio, que tal y como recogió Fabiani:

\begin{abstract}
“Aquel Pino, à cuya sombra predicó el V. P. Fr. Benito [...] en el mismo sitio, sostenido de sus mismas raízes, [...] sin que al discurso de 273 años, desde el mencionado sucesso, haya recibido su tronco, que es de más de veinte palmos, y muy grueso, lesión alguna, ó podredumbre, ó carcoma. [...] Este ha sido llamado siempre en lengua del país: El pi Sant. [...] En tantas ocasiones de guerra [...] no se atreven á tocar el respetable Pino [...] Contóme un religioso que con mucha frequencia [...] muchos Marineros, y personas estrangeras, preguntaban [por él] Y mostrándoselos, unos se arrodillaban, otros lloraban, llenos de respeto y devoción" (Fabiani, 1763, pp.39-41).
\end{abstract}

La otra edificación fácilmente identificable es el Castillo de Santa Bárbara, situada sobre el monte Benacantil, de gran importancia estratégica y militar3. Este lugar está ligado a la ciudad desde su fundación por Amílcar Barca en el siglo III a.C.

El tercer lienzo, representa El milagro de las Tres Faces [4] acaecido tras la predicación de fray y el más importante de los tres pues:

\footnotetext{
"la aparición de las otras dos Fazes [demuestra] que esta de Alicante sea la tercera, y original, como la de Roma, y de Jaén. [Pues si] la hubieran mirado, y atendido [...] hubieran salido fácilmente de su engaño; y sabiendo, como se sabe, que la que havía en Jerusalén, no se halla en aquella Santa Tierra, y solo queda la tradición de haver sido trasladada a Roma; creerían con nosotros y afirmarían sin
}

\footnotetext{
3 Este accidente geográfico fue empleado por los historiadores de esta época para explicar porque "Elche jamás pudo ser la Ilice antigua, como no lo pudo ser tampoco Orihuela" porque era "claro que el término Alicant en lengua del país, era una derivación de Ilicant, como llamaron los moros a la ciudad de Ilici, por lo tanto, Alicante no solamente era la Ilice romana sino que también fue la Alona griega" (Maltés y López, 1991, ed., p.216).. Esto se debía a Plinio y Ptolomeo situaban a Ílici junto al mar, a dos leguas del río Segura y junto a una sierra, entendida por estos autores como el Benacantil. Durante el siglo XVII la ciudad reivindicó estos supuestos orígenes clásicos, como lo podemos ver en las iniciales de su escudo en este momento CIIA (Colonia Iulia Ilici Augusta), para conseguir diferentes prebendas y establecer su propia sede catedralicia. No obstante, algunos intelectuales de la época como el conde de Lumiares ya identificaron correctamente los orígenes de la ciudad con la antigua Lucentum, aunque hasta bien entrado el siglo XIX, cuando se descubrió el yacimiento de Ilici en la Alcúdia (término municipal de Elche) Alicante siguió reivindicándose como su sucesora.
} 
duda, que esta es la de Jerusalén; y por consiguiente una de las tres" (Fabiani, 1763, pp.44-45).

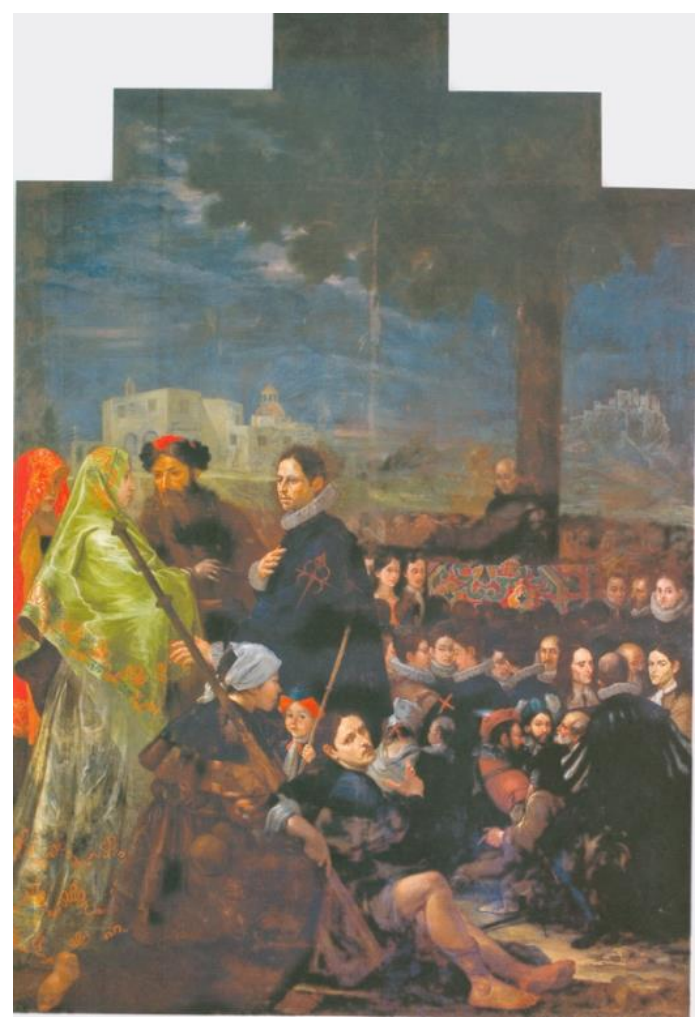

4. El milagro de las Tres Faces, ca.1677- 1680. Óleo sobre lienzo. 338 x $238 \mathrm{~cm}$. Monasterio de la Santa Faz (Alicante). A la derecha, de pie y en primer plano y mirando al espectador se muestra el retrato de Nicolás de Bussy realizado por Senén Vila en "El obispo Zumárraga" (1706-Museo de América) en base al cual Hernández Guardiola ha realizado su identificación. Junto a él, en segundo plano, sentado y mirando al espectador este mismo autor a identificado a Conchillos

En la escena aparece representado en un primer plano el pueblo de Alicante, otra vez en su doble función de elegido por la reliquia y testigo y principal valedor de los milagros, entre los que encontramos los supuestos retratos de Conchillos y de Nicolás de Bussy (Hernández, 1988, p.40). Tras ellos se desarrolla la acción principal con el padre Fray Benito arrebatado hacia los cielos con la Santa Faz y la aparición de los otros dos santos rostros en un rompimiento de gloria con abundantes angelitos.

El lienzo de los Los jurados de Alicante adorando a la Santa Faz, [5] es un retrato grupal de los comitentes de la obra y principales valedores de la reliquia. Su situación junto al relicario de la Santa Faz no es casual, pues en torno a él y su apertura había todo un protocolo codificado en el Estatuto XII de los Generales concedidos por Mariana de 
Austria en 1669 (Mingot, 1876, p.243). La pintura de los Jurats demuestra el alto grado de estima y autoconciencia que el ayuntamiento de Alicante tenía de sí mismo, sobre todo si tenemos en cuenta y este espacio fue un lugar de su poder y piedad personal pues:

"Mandaron ilustrar y adornar el Camarín, en donde se dexa ver la Santa Reliquia con mucho oro, marmoles y finas pinturas, que representan los principales Prodigios y Milagros, que obró el Señor [...], no perdonando á expensas algunas, aunque muy quantiosas en obsequio a la Santissima Faz” (Fabiani, 1763, p.64).

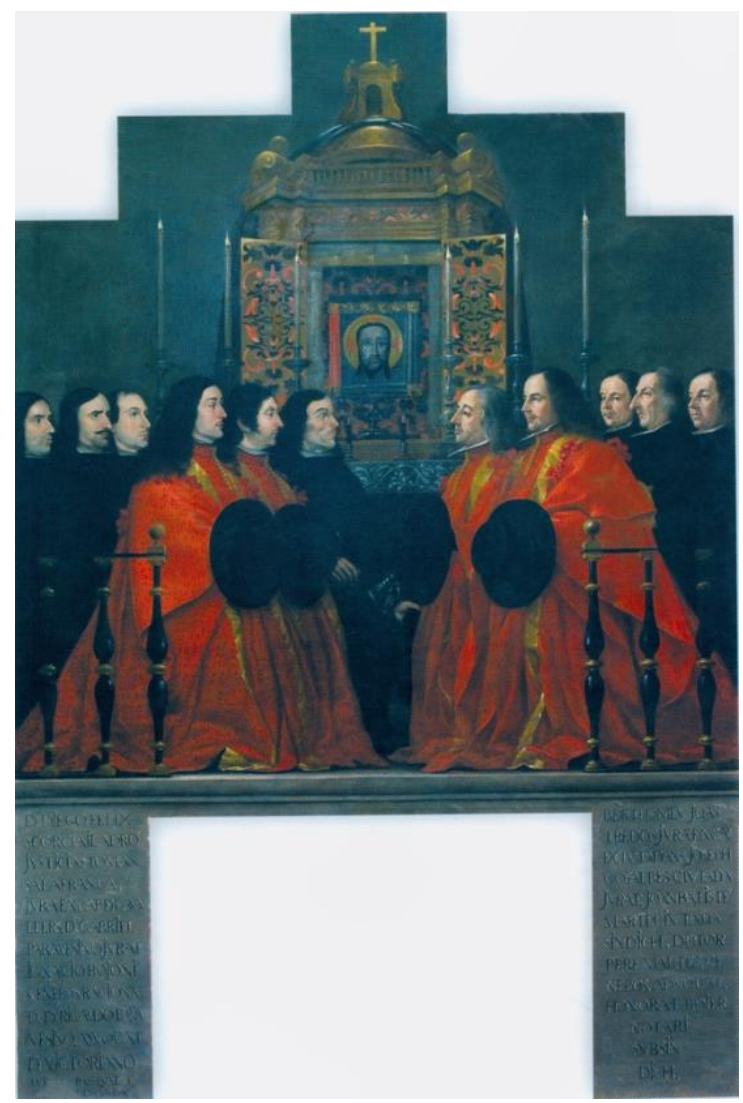

5. Juan Conchillos Falcó. Retrato de los jurados de Alicante venerando a la Santa Faz, ca.1677-1680. Óleo sobre lienzo. 338 x $238 \mathrm{~cm}$. Monasterio de la Santa Faz (Alicante)

\section{CONCLUSIONES: LOS LIENZOS DE LA SANTA FAZ ENTRE PINTURA RELIGIOSA Y PINTURA DE HISTORIA}

Como anteriormente hemos demostrado los lienzos de la Santa Faz ponen de manifiesto la necesidad de realizar relecturas y contextualizar las obras comisionadas por instituciones en el tiempo, el espacio y las políticas emprendidas por las mismas, así como 
el estudio amplio de fuentes para entender lo representado, pues en situaciones como la abordada, cada elemento de la pintura tiene una significación. Por ello, el análisis de las fuentes de la discusión sobre la Santa Faz, no abordadas hasta el presente artículo y la importancia de la representación topográfica real en las pinturas, nos llevan a pensar que en un momento en el que no había separación entre lo religioso y lo civil, estas pinturas fueron encomendadas por el Consell de la ciudad de Alicante con una doble misión: justificar sus reivindicaciones sobre la Santa Faz y documentar los momentos más importantes de la historia reciente de Alicante; reivindicando así mismo su identificación con la casi mítica ílici "cuya christiana antiguedad estaba demostrada por los prodigios allí acontecidos" (Ibídem). Unas reivindicaciones políticas que pretendían trasladar la capitalidad de la Gobernación de Orihuela a Alicante y liberarla del control de esta ciudad.

De esta manera, como mover la Gobernación era más difícil que instalar una nueva sede catedralicia pretendieron basándose en los orígenes clásicos, en la antigua sede diocesana de Ílici y en los prodigios de su cristiana antigüedad crear una nueva sede diocesana pues:

"Importa mucho que se recupere la sede catedralicia de Ilice, en la ciudad de Alicante, su heredera natural, no sólo por haber sido esta de las más antiguas y más prolíficas de la España, sino por haber sido evangelizada por dos apóstoles, Santiago, que atracó en el puerto de Cartagena para difundir el evangelio en esta región y San Pablo, quien la leyenda cuenta que entró a España por el puerto de Ilice, que desde entonces se llama Santa Pola en su honor. Habiendo sido su piedad demostrada y continuada no solamente con las imágenes escondidas y veneradas durante los tiempos de los moros, sino con la venida de la Faz de Nuestro Señor para ofrecerles su infinita protección que es uno de los principales prodigios acaecidos en este nuestro reino" (Ibídem, p.216). 


\section{REFERENCIAS BIBLIOGRÁFICAS}

Belting, Hans (1997). La vraie image : croire aux images? Paris: Gallimard.

- (1998). Image et culte : une histoire de l'image avant l'époque de l'art. Paris: Les Éditions du Cerf.

Bendicho, Vicente (1960 ed.). Crónica de la muy ilustre, noble y leas ciudad de Alicante: acabada en la misma ciudad, el año del señor 1640. Alicante: Instituto de Estudios Alicantinos.

Biosca i bas, Antoni (2014) "L'antic ofici alacantí de Santa Faç”, La rella, n²7, pp.1129.

Calabrese, Omar; Stoichita, Victor I (2015). La verónica de Zurbarán. Madrid: Casimiro Libros.

Cañestro Donoso, Alejandro (2015). Arquitectura y programas artísticos en la provincia de Alicante durante la Edad Moderna. Madrid: CSIC.

Cutillas Bernal, Enrique (1995). El patronato de la ciudad de Alicante sobre el Monasterio de la Santa Verónica en la huerta de la ciudad (1518-1804). Tesis doctoral. Universidad de Alicante.

- (1996). "La polémica ilustrada sobre la reliquia de la Santa Faz de Alicante: un ataque a la Compañía de Jesús”, Revista de historia moderna, nº15, 1996.

Esplá Rizo, Rafael (1962). La santísima faz de nuestro señor Jesucristo. Alicante: Imprenta de Juan Gisbert.

Fabiani, Joseph (1763). Disertación histórico-dogmática sobre la sagrada Reliquia de la Ssma. Faz de N.S.J.C. venerada en la Ciudad de Alicante. Alicante: Imprenta Municipal. Hernández Guardiola, Lorenzo (1976). "Noticias sobre Bussi y Conchillos en Alicante”. Archivo español de arte, vol.49, n¹96, p.467.

- (1988). El Camarín de la Santa Faz. Alicante: Ayuntamiento de Alicante.

- (1994). Pintura decorativa barroca en la provincia de Alicante. 3 vols. Alicante: Instituto de Cultura Juan Gil-Albert, vol.3. 
Hernández Guardiola, Lorenzo y Sáez Vidal, Joaquín (Coord.) (2006). La Faz de la eternidad. Valencia: Generalitat Valenciana.

Llop, Jaume (1963 ed.). Información ad perpetuam rei memoriam de los milagros ocurridos en la Epifanía de la Santa Faz en Alicante. Alicante: Sucesor de Such Serra.

Maltés, Juan Bautista y López, Lorenzo (1991 ed.). Ilice ilustrada. Historia de la muy noble, muy leal y fidelissima ciudad de Alicante. Alicante: Ayuntamiento.

Martínez Morellá, Vicente (1953). El monasterio de Santa Verónica. Alicante: Ayuntamiento de Alicante, 1953.

Mas i Usó, Pasqual. Justas, academias y convocatorias literarias en la Valencia Barroca (1591-1705). Teoría y práctica de una convención. Valencia: Universidad de Valencia, 1993.

Montojo Montojo, Vicente (2010). "El comercio de Alicante a mitad del siglo XVII según los derechos y sisas locales de 1658-1662 y su predominio sobre el de Cartagena". Murgentana, $\mathrm{n}^{\circ} 122$, pp.43-66.

Sáez Vidal, Joaquín (1974). El Ayuntamiento de Alicante: historia de su construcción y arquitectura. Alicante: Instituto de estudios alicantinos.

- (1985). La ciudad de Alicante y las formas artísticas de la cultura barroca (1691-1770). Alicante: Instituto Juan Gil Albert.

Sáez Vidal, Joaquín y Martínez García, José Antonio (coord.) (2003). La luz de las imágenes (Orihuela). Valencia: Generalitat Valenciana, 2003.

Sala Seva, Fernando (1989). Devocionario y poesías a la Santa Faz. Ayuntamiento: Comisión para el V centenario de la Santa Faz.

- (1991). La verdad sobre la Santa Faz. Ayuntamiento: Comisión para el V centenario de la Santa Faz.

Stoichita, Victor I. (1996) El ojo místico. Pintura y visión religiosa en el Siglo de Oro español. Madrid: Alianza.

Varela Botella, Santiago (2006). “Arquitectura en Alicante durante la Edad Moderna. La ciudad de los comerciantes, en Hernández Guardiola, Lorenzo y Sáez Vidal, Joaquín. La faz de la eternidad. Valencia: Generalitat Valenciana, pp.24-47. 
Viciana, Rafael M. (1502). Libro segundo dela Chronyca dela inclita y coronada ciudad de Valencia y de su reyno. Valencia: Impresso en casa de Jaume Navarro, 1502.

Vidal Bernabé, Inmaculada (1981). La escultura monumental barroca en la Diócesis de Orihuela-Alicante. Alicante: Diputación Provincial, 1981.

- (1990). Retablos alicantinos del Barroco (1600-1780). Alicante: Diputación Provincial, 1990. 